\title{
Does Long Run Purchasing Power Parity (PPP) Hold Within The Southern African Customs Union (SACU)?
}

\author{
Masilo Plitemon Makhetha \\ The National University of Lesotho \\ Department of Economics \\ P.O. Roma, 180 \\ Lesotho
}

\section{Abstract}

This paper employs panel data unit root and co-integration tests, in the spirit of Pedrom $(1995,1998)$ and Larsson et al. (1998, 2001), to investigate the vinlidity or othervise of the PPP hypothesis zuithin the SACU area. We are able to find evidence in support of the PPP hypothesis using Larsson et al. (1998, 2001). The Larsson et al.'s $(1998,2001)$ procedure is an extension of Johansen's $(1988,1995)$ methodology that allozus for estimation of the number of co-integrating relations. This offers an interesting alternative to the residual based co-integration tests.

\section{Introduction}

The Purchasing Power Parity (PPP) hypothesis is the hypothesis that exchange rates between currencies are determined in the long run by the amount of goods and services that each can buy. A basic notion is that in the absence of trade impediments, if the price of tradables were lower in one country than another, traders could gain by buying goods in the cheaper country and selling in the dearer. Consequently, relative price levels determine the equilibrium exchange rate.

The first person to treat PPP as a practical empirical theory is Cassel $(1921,1922)$. PPP can be used for a wide range of applications. For instance, in: choosing the right initial 
exchange rate for a newly independent country; forecasting the real exchange rate and adjusting for price differential in international comparisons of incomes.

This paper employs panel data unit root and cointegration tests to investigate the validity of PPP hypothesis in SACU area. The rationale for using panel data unit root and co-integration techniques is that they offer a significant improvement in addressing the low-power problem of the conventional tests, especially, in developing countries where there are serious data limitations; and facilitate pooling of long run information contained in the panel, while permitting the short run dynamics and fixed effects to be heterogeneous among different members of the panel. Moreover, long-run relations between two integrated panel vectors can exist even though there is no individual time series co-integration (Phillip and Moon, 1999). Most of the conventional tests suffer from size distortions (probability of falsely rejecting the null of "non-stationarity" is high, especially, when the true data generating process (d.g.p) is a nearly stationary process). There is a trade off between size and power in that unit root tests must have either high probability of falsely rejecting the null of non-stationarity when the true data generating process is a nearly stationary process or low power against any stationary alternative (Blough, 1992). They are very sensitive to the choice of lag length, and the inclusion or otherwise of constant and trend terms. Moreover, there is supporting evidence that it is the span of data not the frequency of data that matters for the power of these tests (Pedroni, 1997). Therefore, unit root and co-integration tests based on quarterly data do not necessarily have better power than those based on corresponding annual data. In the light of these data limitations, the use of panel data is being suggested as a 
218 Reruew of Southern African Studies Vol. 12, No. 1 \& 2, 2008

convenient practical alternative that increases the number of observations, hence improvement in the power of unit root tests.

\section{Panel Unit root tests}

Buaf and Jorion (1990), Quah (1990), Levin and Lin (1993, 1995) and Breitung and Meyer (1994) present the firstgeneration panel unit root tests. The idea of panel data unit root tests dates as far back as 1990. Abuaf and Jorion (1990) are probably the first to introduce a panel unit root estimation procedure in an attempt to test the purchasing power parity hypothesis. This was necessitated by the need to increase the power properties of single equation unit root tests that are based on very limited data span.

Generally, a model for $\mathrm{N}$ series and $\mathrm{T}$ time periods that encompasses all panel unit root tests is the following:

$$
\Delta y_{1, t}=\alpha_{1}+\beta_{1, y_{1,1,1}}+\sum_{j=1}^{k_{1}} \delta_{t, 1} \Delta y_{1, t-1}+u_{t, l} \quad \mathrm{i}=1,2, \ldots, \mathrm{N}
$$

$t=1,2, \ldots, T$.

In the spirit of Abuaf and Jorion (1990), all the $\beta_{\mathrm{i}}^{\prime} \mathrm{s}$ are restricted to be identical and the lagged differences are omitted for each of the $N$ equations. The unit root null hypothesis being tested is that $\beta_{1}=\beta=0$ and the alternative is that of stationarity across the panel.

Levin and Lin (1993, 1995) retain the all-or-nothing approach from Abuaf and Jorion. In addition, however, they came up with statistical foundations for the panel unit root tests and tabulated critical values for a range of values of $N$ and $\mathrm{T}$ in models involving either fixed effects or a one common intercept across the panel. Moreover, their specification allows for addition of lagged augmentation terms. However, they made no allowance for contemporaneous cross-correlation of the errors. 
As Breuer et al. (2001) point out, it is incorrect to conclude that rejection of the null hypothesis using the Levin and Lin approach signifies stationarity of all variables in all the members of the panel. Rejection of the null hypothesis of unit root in a panel setting can come up when some, but not all, members of the panel are stationary.

The important modifications of the Levin-Lin test include Papell (1997), O'Connell (1998) and Pedroni (1995, 1997a). These retain the all-or-nothing style, therefore, may lead to serious misinterpretation if applied to mixed panels (Breuer et al., 2001).

Papell (1997) modified the Levin and Lin specification slightly to allow for heterogeneous serial correlation of errors. Moreover, the lag structure can differ across the panel members, but no allowance is made for possible contemporaneous error correlations.

O'Connell (1998) modifies the Levin and Lin specification by making an allowance for contemporaneous cross-sectional dependence in the data. Moreover, O'Connell includes lags of the dependent variable (as regressors) to account for possible serial correlation. However, the lag structure is restricted to be homogeneous across the panel (i.e $\delta$ 's and $\mathrm{k}^{\prime} \mathrm{s}$ are identical).

Pedroni $(1995,1997 a)$ : studied the tests for the null of no co-integration in both homogeneous and heterogeneous panels. In respect of heterogeneous panels, Pedroni (1995, 1997a) provides asymptotic distributions for the test statistics that are appropriate for various cases with heterogeneous dynamics, fixed effects and individual specific deterministic trend. Pedroni's (1997a) tests are suitable for the case with common autoregressive roots under the alternative and also permit heterogeneity of the autoregressive root under the alternative. 
220 Revie'u of Sonthern Africun Studie's Vol. 12, No. 1 \& 2, 2008

A major setback as far as the Levin and Lin specification is concerned is that identical orders of integration are imposed across the panel. As noted earlier on, the null hypothesis is that all series contain a unit root, while the alternative is that all series are stationary. Breuer et al. (2001) question the correctness of this approach. In particular, they demonstrate with Monte Carlo simulations how this procedure performs in panels with different orders of integration. Their findings show that rejection of the null hypothesis is possible even with just one stationary member of the panel and the rejection rate increases with the number of $I(0)$ series in the panel. It is noteworthy, however, that though the null may be correctly rejected, the alternative of "all-stationary" is false in mixed panels.

Having recognized the problem inherent in the Levin and Lin's "all-or-nothing approach, Im et al. (1997), Maddala and Wu (1997), Sarno and Taylor (1998), Taylor and Sarno (1998) and Wu and $W u$ (1998) provide second-generation panel unit root tests that permit the autoregressive coefficient to differ among the members of the panel under the alternative hypothesis. In respect of the secondgeneration panel unit root tests, rejection of the null hypothesis implies that "not all members of the panel are non-stationary". This sounds plausible given that in real life situation mixed panels cannot be avoided.

Im et al.'s (1997) test statistic is a simple average of the tstatistics on the $\beta_{\text {i's }}$ produced by $N$ single-equation ADF test. Since the ' $N$ ' ADF equations are independent, then their test allows different auto-regressive coefficients as well as different lags structures in the panel ( $\mathrm{N}$ individual series). Although this is a significant improvement over the "all-ornothing" approach, it does not account for contemporaneous cross-correlations. 
Maddala and Wu's (1997) approach is similar to Im et al. (1997), but they construct the Fisher test statistic using pvalues corresponding to the individual t-statistics on the $\beta_{3}$ 's.

Wu and Wu (1998) adapt both Im et al. (1997) and Fisher tests to allow for the contemporaneous correlations of the residuals using seemingly unrelated regression (SUR) estimation.

Sarno and Taylor (1998) and Taylor and Sarno (1998) provide a multivariate augmented Dicky-Fuller test (MADF) that is based on SUR estimation of the unrestricted version of the model above. The MADF allows for both heterogeneous lags structures and contemporaneous error correlations across the panel. Heterogeneous autoregressive coefficients are permitted across the panel under the alternative hypothesis.

In a nutshell the second-generation panel unit root tests acknowledge the fact that there can be a mixture of stationary and unit root processes in the panel under the alternative hypothesis. However, these tests are incapable of roviding information pertaining to the exact mix of series in the panel when the null hypothesis is rejected. Consequently, Breuer et al. (2001, 2002) propose the tests that use the method of seemingly unrelated regressions applied to a panel ADF equations in which the autoregressive coefficients are heterogeneous across the panel. These tests are capable of providing the researcher with information pertaining to the exact mix of series in the panel when the null hypothesis is rejected. Although the Breuer et al. 's $(2001,2002)$ SURADF test is, by and large, more powerful than the single-equation tests, its power can be modest if the number of time series observations is 100 or less and the largest autoregressive root is close to one. Other panel data unit root tests out-perform the SURADF test in 
this case. The gains from using SURADF are, also, reduced when the residual cross-correlations are low (Breuer, 2002).

It is noteworthy that, though the second-generation tests offer a significant improvement over the Levin-Lin test, the information they provide under the alternative hypothesis is of limited practical significance. The main trouble with these tests is that they are incapable of providing information about the mix and identity of the series for which the alternative hypothesis holds (Breur, 2001, 2002).

\section{Co-integration Tests}

In respect of co-integration tests, notable studies include Pedroni's $(1995,1998)$, Larsson et al. $(1998,2001)$ and Groen and Kleibergen 2003. Pedroni's (1995, 1998) tests are residual-based co-integration tests. Pedroni (1995, 1998) considers several types of specifications, homogeneous and heterogeneous models. Heterogeneous models allow for different individual effects by introducing parameters that can vary across individuals. Pedroni's panel co-integration tests have been used in several empirical studies including, Pedroni (1997), Nagayasu (1998), and Canning and Pedroni (1999). The first two employ Pedroni's tests to test the PPP hypothesis, while the latter applies the same tests to test for co-integration between infrastructure variables and GDP.

Pedroni (1995, 1998) describes a method to use in implementing tests for the null of "no co-integration" for the case with multiple regressors and provides appropriate critical values. The tests allow for heterogeneity among individual members of the panel, heterogeneity in both the long run co-integrating vectors and heterogeneity in the dynamics associated with short run deviations from these co-integrating vectors. 
Unlike in a conventional time series case, Pedroni (1995, 1998) does not address issues regarding normalization and/or number of co-integrating relationships but focuses solely on reporting critical values for the case where the null hypothesis is "no co-integration" versus the alternative of co-integration. The emphasis is on whether or not the variables are co-integrated (not on the number of cointegrating vectors). Panel co-integration techniques allow researchers to, selectively, pool information regarding common long run relationships from across the panel while still allowing the associated short run dynamics and fixed effects to be heterogeneous across different panel members. This, also, helps circumvent the problem of low power that is common in conventional tests, especially, when applied to series of only moderate length. In panel co-integration tests, the null hypothesis is that for each member of the panel, the variables in question are not co-integrated. The alternative hypothesis is that for each member of the panel there exists a single co-integrating vector (although the co-integrating vector need not be the same for all members). More importantly, the panel co-integration tests not only allow the dynamics and fixed effects to differ across members of the panel, but also allow the co-integrating vector to differ across members under the alternative hypothesis.

Larsson et al. $(1998,2001)$ and Groen and Kleibergen 2003 are based on Maximum Likelihood-based inference for vector auto-regressive models developed by Johansen (1988) and Johansen and Juselius (1990). Their panel tests offer an interesting alternative to residual-based co-integration tests (Pedroni, 1995, 1998) because they allow for estimation of the number of co-integrating vectors that the different individuals have in common within a panel. It is nuteworthy, however, that Larsson et al. $(1998,2001)$ assume 
a block diagonal cross-section covariance structure while Groen and Kleibergen (2003) allow for an unrestricted disturbance covariance matrix within a panel. This permits instantaneous feedback between the different members of the panel.

\section{The model and methodology Testing for PPP}

We consider the following regression in a panel framework:
1.1
$p_{u}^{d}=\alpha_{1}+\beta_{1} p_{u}^{\prime}+\varepsilon_{u}$
$\mathrm{t}=1,2, \ldots, \mathrm{T} ; \mathrm{i}=1$,

$2, \ldots N$,

where $p_{d}^{d}$ and $p_{t}^{\prime}$ are, respectively, domestic prices and foreign currency prices; $\mathrm{T}$ and $\mathrm{N}$ are number of observations and the number of individuals members of the panel, respectively. In common with Pedroni $(1995,1998)$ and Larsson et al. $(1998,2001)$, the slope coefficients $\beta$ s are allowed to vary across individual members of the panel. Moreover, member specific intercept $\alpha_{1}$ (fixed effects parameter) is permitted to vary across individual members. Also, an allowance is made for deterministic time trends that are specific to individual members of the panel.

According to the cointegration literature, PPP holds if $p^{d}$ and $p_{\|}^{\prime}$ are individually non-stationary but cointegrated. However, the two price measures should be expressed in terms of the same currency. Consequently, equation (1.1) becomes:

1.2

$$
p_{\|}^{\prime \prime}=\alpha_{1}+\beta_{1} p_{n}^{\prime \prime}+\varepsilon_{u}
$$

where $p_{u}^{\prime \prime}$ is $\left(p_{n}^{\prime} E_{\mathrm{it}}\right)$ and $E_{\mathrm{it}}$ is the exchange rate (defined as the price of foreign currency in terms of domestic currency). 


\section{Review of Econometric Methods}

\section{Panel Data Unit Root Tests}

In common with Pedroni (1998), we consider the following Model:

1.3

$$
\begin{aligned}
& y_{u}=\alpha_{1}+\delta_{1} t+\beta_{1} X_{1 u}+\beta_{2 i} X_{2 u}+\ldots+\beta_{m t} X_{m u}+e_{u \prime}, \\
& t=1,2, \ldots, T ; i=1, \ldots, N ; m=1, \ldots, M
\end{aligned}
$$

where $T$ is the number of observations over time, $N$ stands for the number of individual members in the panel, and $M$ represents the number of regression variables.

In this case there will be $N$ different equations, each of which has $M$ regressors. Of notable importance is the fact that the slope coefficients $\beta^{\prime}$ s are allowed to vary across individual members of the panel. Moreover, there is a member specific intercept $\alpha_{1}$, fixed effects parameter that is permitted to vary across individual members.

In respect of within-dimension statistics (panel cointegration statistics), the null hypothesis is:

$$
H_{0:} \rho_{2}=1 \text {, for all } \mathrm{i} \text {, }
$$

against the alternative

$$
H_{1}: \rho_{l}=\rho<1 \text { for all } i \text {, }
$$

so that a common value for $\rho_{l}=\rho$ is assumed. On the contrary, for the between-dimension statistics (group-mean panel cointegration statistics) the null hypothesis is:

$$
H_{0}: \rho_{1}=1 \text {, for all } \mathrm{i} \text {, }
$$

against the alternative,

$$
H_{1}: \rho_{l}<1 \text {, for all } l \text {, }
$$

where $\rho_{1}$ is the auto-regressive coefficient of the variable in question.

The statistics defined below are extracted from Table I of Pedroni (1998). The statistics as defined in Table I of Pedroni (1998) are used for co-integration tests, therefore, for unit root tests, appropriate adjustment is necessary. For instance, estimated errors should be replaced by the variables in 
question. The tests can be used for both purposes (cointegration and unit root tests). For instance, given the following equation: $y_{11}=\beta^{\prime} y_{21}+u_{1}$, if $u_{t}$ has a unit root, then $y_{1 t}-\beta^{\prime} y_{2 t}$ is not a co-integrating relationship.

Group t-Statistic:

(non-parametric)

$$
N^{-1 / 2} \bar{Z}_{t, j} \equiv N^{-12} \sum_{i=1}^{N}\left(\hat{\sigma}_{i}^{2} \sum_{i=1} \hat{e}_{H-1}^{2}\right)^{-1 / 2} \sum_{i=1}^{t}\left(\hat{e}_{i+1} \Delta \dot{e}_{n}-\hat{\lambda}_{i}\right)
$$

Group t-Statistic:

(parametric)

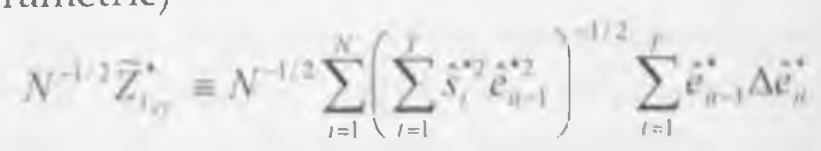

Where

$$
\dot{\lambda}_{1}=\frac{1}{T} \sum_{n=1}^{t}\left(1-\frac{s}{k_{+}+1}\right) \sum_{j=1+1}^{t} \dot{\mu}_{i} \dot{\mu}_{\mu-\ldots},
$$

$$
\hat{s}_{i}^{2} \equiv \frac{1}{T} \sum_{i=1}^{T} \hat{\mu}_{c}^{2}
$$

$\hat{\sigma}_{1}^{2}=\hat{s}_{i}^{2}+2 \dot{\lambda}_{1}$

$\widetilde{\sigma}_{N i}^{2} \equiv \frac{1}{N} \sum_{i=1}^{N} \hat{L}_{i l i}^{2} \hat{\sigma}_{i}^{2}, \hat{s}_{i}^{* 2} \equiv \frac{1}{T} \sum_{i=1}^{T} \hat{\mu}_{n}^{2}, \widetilde{s}_{N i}^{2} \equiv \frac{1}{N} \sum_{i=1}^{N} \tilde{s}_{i}^{*}$,

$\hat{L}_{11,}^{2}=\frac{1}{T} \sum_{i=1}^{T} \hat{\eta}_{i t}^{2}+\frac{2}{T} \sum_{s=1}^{1}\left(1-\frac{s}{k_{t}+1}\right) \sum_{i=x+1}^{T} \hat{\eta}_{i t} \hat{\eta}_{i t-v}$,

The residuals $\hat{\mu}_{u}, \hat{\mu}_{n}$ and $\hat{\eta}_{u}$ are obtained from the following:

$\hat{e}_{n}=\dot{\rho}_{1} \dot{e}_{n-1}+\dot{\mu}_{n}$,

$$
\hat{e}_{11}=\hat{\rho}_{1} e_{11-1}+\sum_{k=1}^{k_{1}} \hat{\gamma}_{l k} \Delta \hat{e}_{n-k}+\ddot{\mu}_{\| \prime}
$$

$\Delta y_{u}=\sum_{m=1}^{M} \hat{b}_{m} \Delta \gamma_{m}+\hat{\eta}_{\|}$, repectively. 
For the non-parametric statistics, the auto-regression is of the form:

$$
\hat{e}_{11}=\hat{\rho}_{11-1}+\hat{\mu}_{n} .
$$

The residuals are used to compute the long run variances of $\hat{\mu}_{l 1}$ denoted by $\hat{\sigma}_{2}^{2}$. This, in turn, is used to compute $\dot{\lambda}_{1}$ defined by: $\dot{\lambda}_{1}=\frac{\dot{\sigma}^{2}-\dot{s}_{i}^{2}}{2}$, where $\dot{s}_{+}^{2}$ denotes a simple variance of $\hat{\mu}_{l}$. For the parametric statistics, the autoregression is of the form:

$\dot{e}_{n}=\hat{\rho}_{1} \hat{e}_{n-1}+\sum_{k=1}^{k_{1}} \dot{\gamma}_{1 k} \Delta \vec{e}_{11-k}+\hat{\mu}_{n}^{*}$.

The residuals are used to compute the simple variance of $\ddot{\mu}_{i}$ that is denoted by $\vec{s}_{i}^{2}$.

The standardised versions for both parametric and nonparametric statistics have the same asymptotic distribution: $N \cdot \bar{Z}_{1}-\bar{\theta}_{2} \sqrt{N} \rightarrow N\left(0, \bar{\psi}_{22}\right)$, where $\bar{\theta}$ and $\tilde{\psi}$ are, respectively, the vector of means and covariance matrix of the vector functional. The statistics are normally distributed as indicated above. The values of the statistics diverge to negative infinity. Large negative values imply rejection of the null.

\section{Co-integration Tests}

In common with Larsson et al. $(1998,2001)$ we consider the following model:

1.3.

$$
Y_{t i}=\sum_{k=1}^{k_{1}} \Pi_{t k} Y_{1, t-k}+\varepsilon_{n}, \quad \mathrm{i}=1, \ldots, \mathrm{N}
$$

and the heterogeneous error correction model becomes: 


$$
\Delta \mathrm{Y}_{\|}=11, \mathrm{Y}_{1, t-1}+\sum_{k=1}^{k_{i}-1} \mathrm{I}_{i k} \Delta \mathrm{Y}_{1, k}+\varepsilon_{n} \quad i=1, \ldots, \mathrm{N}
$$

and $\varepsilon_{n} \sim N_{p}\left(0 . \Omega_{,}\right)$,

where $N, T$ are, respectively, number of groups and the observation period. All the coefficient matrices, $\Pi_{1}$, are of order $p \times p$ ( $p$ stands for the number of variables in each group). If $\Pi$, is of reduced rank, $r$, then it may be defined as $\Pi_{1}=A_{1} B$, where $A_{1}$ and $B_{1}$ are matrices of order $p \times r$, and full column rank. The error-correction molel (1.4) is similar to the one presented by Johansen (1995) where multivariate co-integration analysis is carried out using data set relating to an individual group as opposed to a panel data. The Johansen's (1995) reduced rank estimation procedures facilitate estimation of the rank of $\left[I_{1}\right.$, and testing of hypotheses on $A_{\mathrm{i}}$ and $B_{1}$. In particular, we note that dropping group index $i$ from (1.4) leaves us with the well known Johansen (1995) error-correction model.'

The panel test of co-integrating rank is based on the group specific rank test as presented in Johansen (1995). The null hypothesis is that all the $N$ groups in the panel have the same number of co-integrating relationships among the $p$ variables $\left(r_{1}=r\right)$. The rank hypothesis is given by:

$$
H_{0}: \operatorname{rank}\left(\Pi_{1}\right)=r_{1} \leq r \text {, for } i=1 \ldots . ., N
$$

against the alternative that

$$
H_{1}: \operatorname{rank}\left(\Pi_{1}\right)=p \text { for all } i=1, \ldots, N
$$

The trace statistic (Likelihood ratio test) for group $i$ is given by:

$$
L R_{i l}\left(H(r) \backslash H(p)=-2 \ln Q_{i l}(H(r) \backslash H(p))=-2 \ln Q_{\| l}(H(r) \backslash H(p))\right.
$$

The LR-bar statistic, the average of the $\mathrm{N}$ individual trace statistics is defined as: 
IR、 $(H(r) \backslash H(p))=\frac{1}{N} \sum_{i=1}^{N} L R_{i l}(H(r) \backslash H(p))$.

A standardized version of this $L R$-bar statistic that is proposed as a basis for the panel co-integration rank test is defined as:

$$
\gamma_{L R}(H(r) \backslash H(p))=\frac{\sqrt{N}}{\sqrt{\operatorname{Var}\left(Z_{k}\right)}}\left[L \bar{R}_{\Lambda T}(H(r) \backslash H(p))-E\left(Z_{k}\right)\right],
$$

where $E\left(Z_{k}\right)$ and $\operatorname{var}\left(Z_{k}\right)$ are, respectively, mean and variance of the asymptotic trace statistic (required for the calculation of the standardized panel rank statistics). The standardized statistic is said to converge to a normal distribution as $N$ and $T$ approach infinity ${ }^{11}$ given he following assumptions and lemmas (Larsson et al., 1998, 2001): first, the data generating process is covariance stationary for each group. This ensures that the variables being dealt with are integrated of order one, at most. Second, the stochastic term in equation (1.4) has the usual properties assumed in conventional regression analysis, namely, that $E\left(\varepsilon_{n}\right)=0$ and

$$
E\left(\varepsilon_{11} \varepsilon_{\| \prime}\right)=\left\{\begin{array}{lll}
\Omega, & \text { for } & i=j \\
0 & \text { for } & i \neq j
\end{array}\right.
$$

Finally, the derivation of the standardized statistic is based on the Lemma that the second moment, $E\left(Z_{k}\right)$ exists and is finite. The existence of the first two moments of $Z_{k}$ is needed for establishing the asymptotic distribution of the panel rank statistic using central limit theorem (Larsson et al., 1998, 2001). The requirement that $T \rightarrow \infty$ guarantees the convergence of the individual trace statistic to $Z_{k}$, while $N \rightarrow$ $\infty$ is a requirement for the central limit theorem to apply. Note that $N$ and $T$ increase to infinity in such a manner that $\sqrt{N T}{ }^{*} \rightarrow 0$ (for $k>0$ ). This condition ensures that the error 
caused by using the asymptotic mean $E\left(Z_{T}\right)$ instead of the finite sample mean

$E\left(-2 \ln Q_{T}\right)$ vanishes as $N$ and $T$ approach infinity (Larsson et al., 1998, 2001).

Larsson et al. $(1998,2001)$ provide the relevant expected mean, $E\left(Z_{k}\right)$ and variance, $\operatorname{vir}\left(Z_{k}\right)$ that are used in the panel rank test for a case of $k=p-r \quad(=1, \ldots, 12)$. They propose a secuential testing procedure similar to that of Johansen (1988). Given the hypothesis that: $H_{0}: \operatorname{rank}\left(\Pi_{1}\right)=r_{1} \leq r$ for all $i$, they, first test $r=0$, followed by $r=1$ (if $r=0$ is rejected). This sequential procedure continues till the null is not rejected. They conduct a one-sided Z-test, such that the null hypothesis is rejected if :

$$
\gamma_{l \cdot R}(H(r) \backslash H(p))>Z_{1-\alpha},
$$

where $Z_{1-a}$ is the standardized normal $(1-a)$ quantile.

\section{Empirical results}

Our study employs quarterly time series data from the four SACU member countries, namely, Botswana, Lesotho, Swaziland and Namibia. The data cover the period 1981:1 to 2000:4. The price series used are CPI's for the four countries. Moreover, the South African Rand is used as a base currency.

First, we investigate the time series properties of the data (establishing whether or not the variables in question are stationary). The present study employs ADF version of group mean panel unit root test suggested by Pedroni (1995, 1997a, 1998). In particular, the group- $t$ test statistic is used. Pedroni provides the program used for implementing the tests.

Finally, we use the Larsson et al. $(1998,2001)$ tests to establish existence or otherwise of cointegration among the variables in question. Although Kleibergen's (2003) tests 
may perform better than Larsson et al.'s $(1998,2001)$ tests, the program for implementing the tests is not yet available to us.

\section{Unit root tests}

The unit root test results are summarized in Table 1.1. Table 1.1 shows the results of both individual and panel unit root tests, whose aim is to establish the order of integration of each variable. We use the group-t test statistic proposed by Pedroni (1995, 1998). The null hypothesis is "nonstationarity" while the alternative is "stationarity". As highlighted above, the Pedroni's tests allow for heterogeneity across individuals. Moreover, the tests provide both individual and panel statistics. The statistics are distributed as $N(0,1)$ under the null hypothesis of unit root. Large negative values lead to rejection of a unit root in favor of stationarity. The lag selection procedure adopted here is that suggested by Campbell and Perron (1991). The procedure starts with an upper bound, $\mathrm{k}=\mathrm{K}_{\max }$. If the last lag is insignificant, then $\mathrm{k}$ is reduced by one till a significant lag is found. In some cases no lag is found significant, therefore, $k$ is set equal to zero. We find $k=4$ to be the most appropriate lag length. It is worth noting that as in the conventional unit root tests, over fitting the model could be costly in terms of power, while under fitting may introduce size distortions (Luintel, 2001).

If the null cannot be rejected, then one may assume that the variables are $1(1)$. It may be advisable to test for unit root in first differences to check for a higher order of integration. In that eventuality, however, the null is that the variables are I(2) against the alternative that they are I(1). Therefore, the test expressed in levels on Table 1.1 tests the null that a series is $I(1)$ against the alternative of stationarity, $I(0)$. The 
second test, expressed in first difference, tests the null hypothesis that the series is $I(2)$ against the alternative of I(1). In both cases different scenarios are considered. The first column depicts a situation whereby only a constant is allowed (no time trend). The second column depicts a case where both constant and trend are included. Common time dummies are included so as to purge the data of any common effects across the countries. The fixed effects parameter (member specific intercept) are permitted to vary across individual members of the panel. Moreover, we allow for member specific time trends. The two scenarios depicted in Table 1.1 lead to different conclusions regarding the stationarity or otherwise of the variables, especially, in the case of $p^{\mathrm{d}}$. With "constant only" specification, $p^{\text {d }}$ appears to be stationary for all the individual countries in the panel. But with "constant plus trend" specification, $p^{\text {d }}$ appears to be non-stationary for all the individual countries in the panel. This highlights the sensitivity of the test to the inclusion or otherwise of trend variable in the model. Preliminary tests (graphical analysis) did suggest that the inclusion of a trend term is appropriate. The foreign price, $p^{\text {fe }}$, however, is consistently non-stationary in levels. Both variables appear to be stationary in first differences. The critical values for the ADF statistics for the individual members of the panel are obtained from Mackinon (1991).

If we base our decision on the "constant plus trend" specification then both variables are non-stationary, integrated of order one, at least. In that eventuality, we conclude that the variables are I(1), because the null of nonstationarity, $I(1)$ cannot be rejected in the test expressed in levels, but the null of $I(2)$ is rejected in favor of $I(1)$ in the test expressed in first differences (individual country tests). Note that since heterogeneous lag truncation is permitted, then, 
we have different lag lengths per series per country as presented in brackets in Table 1.1 .

We can draw a similar conclusion from the panel unit root test, because it examines the same hypothesis as in the case of the individual unit root test. Based on the panel test, the null of $I(1)$ (levels test case) cannot be rejected while that of I(2) (first differences test case) is rejected in all the cases. Therefore, as in the case of individual unit root test, the variables in levels are non-stationary while those in first differences are stationary (constant plus trend specification). 
234 Rerie'u of Southern African Studu's Vol. 12, No. I \& 2, 200$) 8$

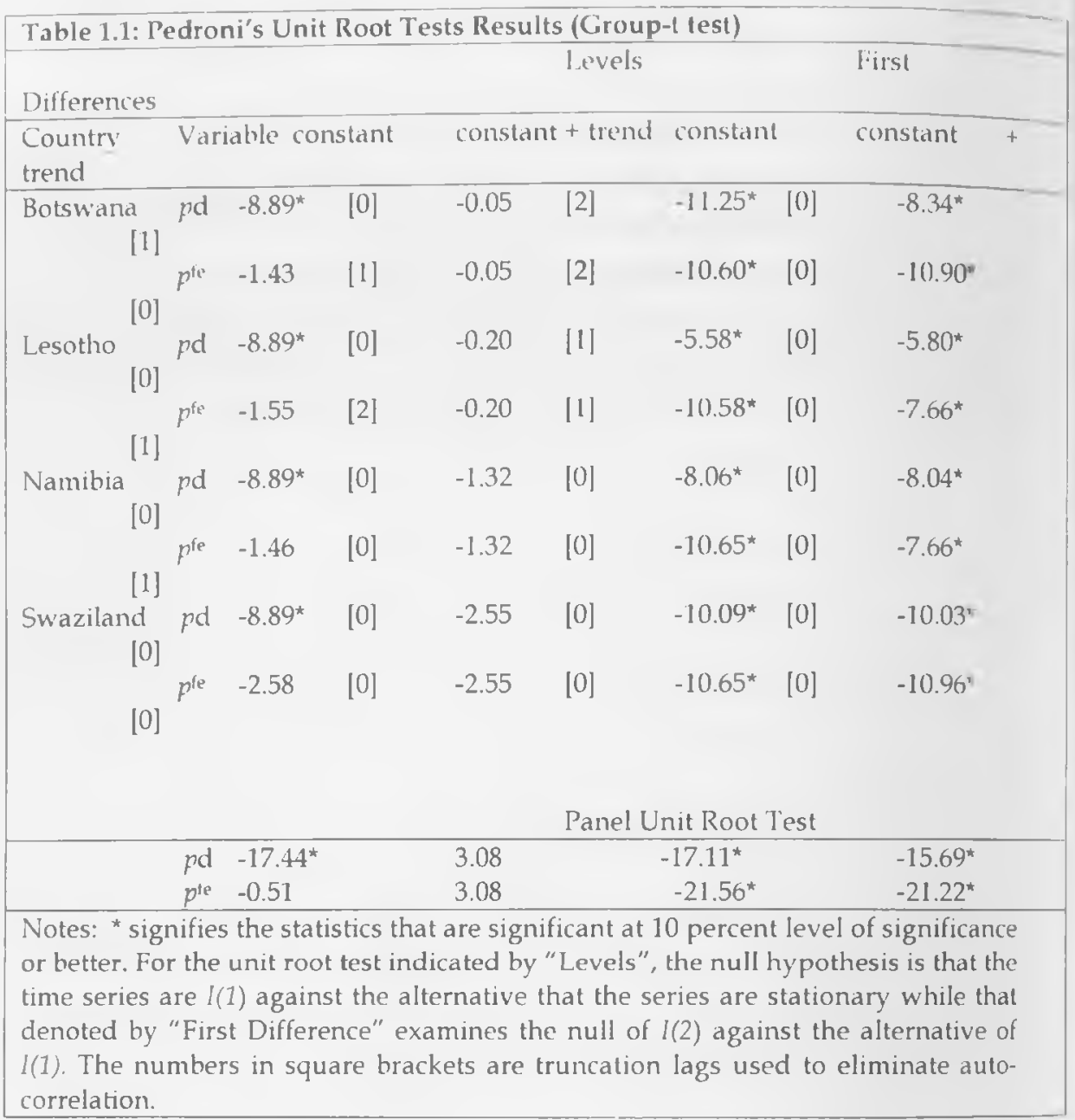

\section{Larsson et al co-integration test}

Larsson et al (1998) offer a panel test for existence of a common co-integration rank. Their test is an attractive alternative to the residual-based co-integration tests. Their rank test allows for estimation of the number of cointegrating relations, as opposed to the two-step residualbased co-integration tests (such as Pedroni's tests). The two- 
step residual-based co-integration tests only deal with the existence of co-integration with an arbitrarily imposed normalization.

In conducting the Larsson et al $(1998,2001)$ tests, we consider the heterogeneous panel error correction model (1.2) above with variable vector:

$$
y_{1 "}=\left(p^{\prime \prime} \cdot p^{\prime \prime}\right) \text {. }
$$

The individual country-by-country and the panel test results are presented in Table 1.2 below. For all four countries, a common lag-order $\left(k_{1}=4\right)$ is selected. The individual country trace test statistics for the hypotheses $H(0)$ to $H(1)$ are presented at the upper part of Table 1.2, while the panel test results are presented at the bottom of the Table. The individual country-by-country test results suggest rank, $r=1$ for Botswana and Lesotho while the rest $r=0$. This suggests existence of cointegration only in the cases of Lesotho and Botswana.

More interestingly, the panel test results suggest existence of one (1) common co-integrating relation. The presence of cointegration between the variables is, according to the cointegration literature, an indication that PPP holds within SACU.

It is noteworthy, however, that though the Larsson et al.'s $(1998,2001)$ approach is capable of determining the number of cointegrating vectors that the different individuals have in common within a panel, it does not control for cross-sectional dependence among the panel, that is, the analysis assumes a block-diagonal cross-sectional covariance matrix. Disregarding the possibility of crosssectional correlation across the individual disturbances may introduce test size distortions. In the case of SACU, chances are high that most price levels are driven by a common external shock (e.g. monetary shocks in South Africa). As a 
be more appropriate in this case, one fails to reject the null hypothesis of non-stationarity. Since the null of $I(1)$ could not be rejected, while that of $I(2)$ was rejected, one is inclined to conclude that the variables are integrated of order one In respect of co-integration tests, we have conducted the Larsson et al $(1998,2001)$ tests.

The Larsson et al $(1998,2001)$ co-integration test offers an attractive alternative to Pedroni's residual based tests. This test is aimed at establishing the existence of a common cointegration rank as opposed to the residual-based tests that do not address the issue of rank order. The individual country-by-country test results suggest rank, $r=1$ for Botswana and Lesotho while for the rest of the countries $r=$ 0 . This suggests existence of cointegration only in the cases of Lesotho and Botswana. In respect of the panel test, which is of more interest in the analysis, it is revealed that there exists one (1) common co-integration rank in the panel. Using this approach, the PPP hypothesis is supported within SACU area. 


\section{References}

Abuaf, N. and Jorion, P. (1990) "Purchusing Potwer Parity in the Long Run". Journal of Finance, 45, pp. 157-174.

Breitung, J. B. and Meyer, W. (1994) "Testing For Linit Roots in Panel Datn: Are Wages on Different Bargaining Levels Cointegrated?". Applied Economics, 26, pp. 353-361.

Breuer, J. B., McNown, R. and Wallace, M. (2001)

"Mislending Inferences from Panel Unit Root Tests With an Illustration From Purchasing Power Parity". Reziezu of International Economics, 9, pp. 482-93.

Breuer, J. B., McNown, R. and Wallace, M. (2002) "SeriesSpecific Unit Root Tests With Panel Datn". Oxford Bulletin of Economics and Statistics, pp. 527-546.

Canning, D. and Pedroni, P. (1999) “Infrastructure and Long Run Economic Growth". Centre for Analytical Economics Working Paper No. 99-(09, Cornell University.

Campbell, J.Y. and Perron, P. (1991) "Pitfalls and Opportunities: What Macroeconomics Should Know About Unit Roots". In O.J. Blanchard and S. Fisher (eds), Macroeconomics Annual, The MIT Press: Cambridge, MA, 141-201.

Groen, J. J. J. and Kleibergen, F. (2003) "Likelihood-Based Cointegration Analysis in Panels of Vector Error-Correction Models". American Statistical Associntion Journal of Business and Economic Statistics, 21(2), pp 295-318.

Im, K.S, Pesaran, M.H. and Shin, Y. (1995) "Testing for Unit Root in Heterogeneous Panels." WP9526, DAE, University of Cambridge.

Im, K.S., Pesaran, M.H. and Shin, Y. (1996) "Testing for Unit Root in Heterogeneous Panels. Mimeo. 
Im, S.K., Pesaran, M.H. and Shin, Y. (1997) "Testing for Unit Root in Heterogeneous Panels". Department of Applied Economics, Cambridge University, Revised Version of Working Paper 9526.

Johansen, S. (1988), 'Statistical Analysis of Co-integration Vectors'. Journal of Economic dynamics,' 12, pp 231 - 254.

Johansen, S. and Juselius, K. (1990), ' 'Maximum Likelihood Estimation and Inference on Co-integration - with Application to the Demand for Money.' Oxford Bulletin of Economics and Statistics, 52, pp $169-210$.

Johansen, S. (1995) "Likelihood-based Inference in Cointegrated Vector Autoregressive Models. Oxford: Oxford University Press.

Larsson, R., Lyhagen, J. and Lothgren, M. (1998) "Likelihood-Based Co-integration Tests in Heterogeneous Panels". Working Paper, Stockholm School of Economics, August.

Larsson, R., Lyhagen, J. and Lothgren, M. (2001),

"Likelihood-Based Co-integration Tests in Heterogeneous Panels". Econometrics Journal, 4, 109-142.

Levin, A. and Lin, C.F. (1993) "Unit Root Tests in Panel

Data: New results. UC San Diego Working Paper.

Levin, A. and Lin, C.F. (1995) "Unit Root Tests in Panel Data: Asymptotic and Finite Sample Properties." Journal of Econometrics in Press.

Luintel, K. B. (2001) "Heterogeneous Panel Unit Root Tests And Purchasing Power Parity." The Manchester School Supplement, pp 42-56.

Mackinon, J.G. (1991) "Critical Values for Co-integration Tests". in R.F. Engle and C.W.J. Granger (eds), Long - Run Economic Relations. Oxford: Oxford University Press, 267 $-276$. 
240 Rerieze of Southerm Africum Studie's Vol, 12, No, 1 \& 2, 2008

Maddala, G. S. and Wu, S. (1997) "A Comparative Study of Unit Root Tests with Panel Data and a New Simple Test." Manuscript, Ohio State University.

Nagayasu, J. (1998) "Does the Long Run PPP Hypothesis Hold for Africa? Evidence from panel Co-Integration Study". IMF Working Paper, WP/98/123.

O'Connel, P. G. J. (1998) "The' Overvaluntion of Purchasing Power Parity." Journal of International Economics, 44, pp 119.

Papell, D. (1997), "Searching for Stationarity: Purchasing Power Parity Under the Current Float." Journal of International Economics, 43, pp 313-332.

Pedroni, P. (1997a) "Panel Co-integration; Asymptotic and Finite Sample Properties of Pooled Time Series Tests with an Application to the PPP Hypothesis; New Results." Working Paper, Indiana University, April (1997).

Pedroni, P. (1998) "Critical Values for Co-integration Tests in Heterogeneous Panel With Multiple Regressors." Working Paper, Indiana University, June (1998).

Pedroni, P. (2000) "Fully Modified OLS for Heterogeneous Co-integrated Panels." Working Paper, Indiana University, April (2000).

Phillips, P.C.B. and Moon, H.R. (1999) "Linear Regression Limit Theory for Nonstationary Panel Data." Econometrica.

Quah, D. (1990) "International Patterns of Growth: Persistence in Cross-Country Disparities." MIT Working Paper.

Sarno, L. and Taylor, M. (1998) "Real Exchange Rates Under the Recent Float: Unequivocal Evidence of Mean Reversion." Economics Letters, 60, pp 131-7. 
Taylor, M. and Sarno, L., "The Behannor of Real Exchange Rates During the Post Bretton Woods Period." Journal of International Economics, 46, pp 281-312.

Wu, Y. and Wu, J.-L. (1998) "Purchasing Power Parity Under the Current lloat: New Evidence From Panel Data Unit Root Tests. Mimeo, SUNY at Buffalo: NY.

I In the case of Johansen (1995), the co-integrating rank hypothesis is specified as $I(r): \operatorname{rank}(\pi) \leq r$, against he alternative that $H(p): \operatorname{rank}(\pi)=p$. The likelihood ratio test, statistic, namely, trace statistic is defined as $-2 \ln Q_{7}[H(r) \backslash H(p)]=-T \sum_{i=r+1}^{p} \ln \left(1-\hat{\lambda}_{i}\right)$, where $\lambda_{1}$ denotes the $i^{\text {th }}$ eigenvalue. The asymptotic distribution of this statistic as presented in Johansen (1995) is given by $-2 \ln Q_{l}[H(r) \backslash H(p)]_{\rightarrow}^{\prime \prime} Z_{k}$, where $z_{b}=\operatorname{tr}\left\{\int_{0}^{1}(d W) W\left[\int_{0}^{1} W W\right]^{-1} \int_{0}^{1} w(d W)\right\}$, and $W$ is a Brownian motion with $k=(p-r)$ dimensions.

$2 N, T \rightarrow \infty$ in a manner that $\sqrt{N} T^{-k} \rightarrow 0$, for $\mathrm{k}>0$. 


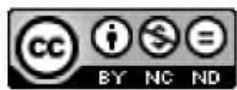

This work is licensed under a

Creative Commons

Attribution - NonCommercial - NoDerivs 3.0 License.

To view a copy of the license please see:

http://creativecommons.ora/licenses/bv-nc-nd/3.0/

This is a download from the BLDS Digital Library on OpenDocs

http://opendocs.ids.ac.uk/opendocs/ 